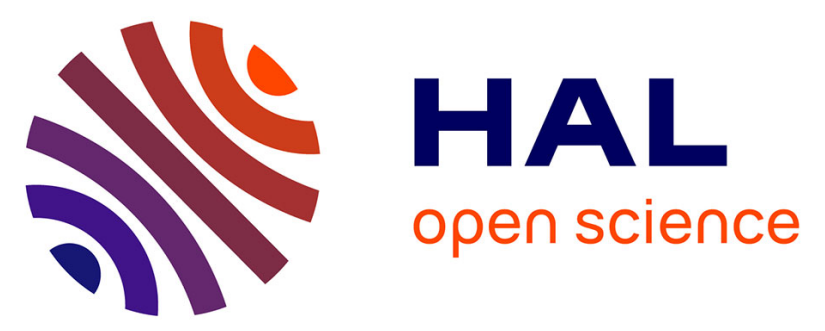

\title{
Impact of Oxygen Transport Properties on the Kinetic Modeling of Polypropylene Thermal Oxidation. II. Effect of Oxygen Diffusivity
}

Alexandre François-Heude, Emmanuel Richaud, Alain Guinault, Eric Desnoux, Xavier Colin

\section{To cite this version:}

Alexandre François-Heude, Emmanuel Richaud, Alain Guinault, Eric Desnoux, Xavier Colin. Impact of Oxygen Transport Properties on the Kinetic Modeling of Polypropylene Thermal Oxidation. II. Effect of Oxygen Diffusivity. Journal of Applied Polymer Science, 2015, 132, pp.1-11. 10.1002/app.41562 . hal-01188930

\author{
HAL Id: hal-01188930 \\ https://hal.science/hal-01188930
}

Submitted on 17 Feb 2017

HAL is a multi-disciplinary open access archive for the deposit and dissemination of scientific research documents, whether they are published or not. The documents may come from teaching and research institutions in France or abroad, or from public or private research centers.
L'archive ouverte pluridisciplinaire $\mathbf{H A L}$, est destinée au dépôt et à la diffusion de documents scientifiques de niveau recherche, publiés ou non, émanant des établissements d'enseignement et de recherche français ou étrangers, des laboratoires publics ou privés. 


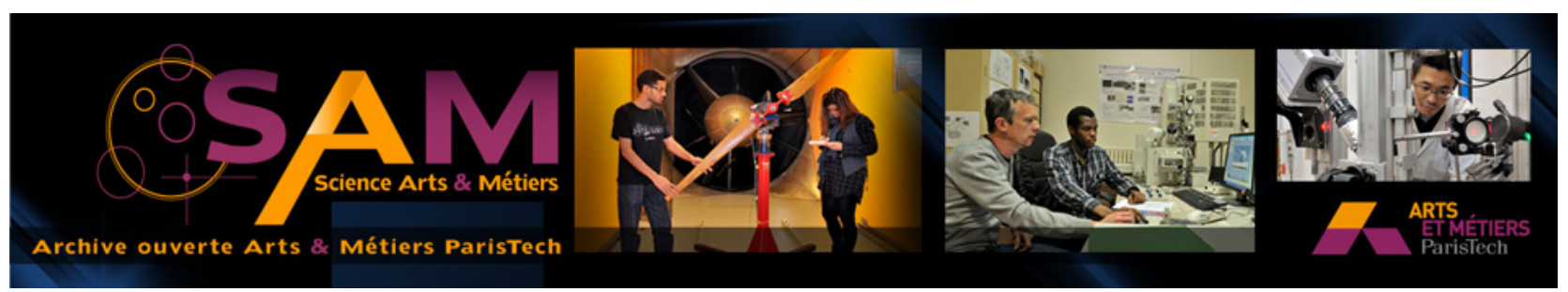

\section{Science Arts \& Métiers (SAM)}

is an open access repository that collects the work of Arts et Métiers ParisTech researchers and makes it freely available over the web where possible.

This is an author-deposited version published in: http://sam.ensam.eu

Handle ID: .http://hdl.handle.net/10985/9875

\section{To cite this version :}

Alexandre FRANÇOIS-HEUDE, Emmanuel RICHAUD, Alain GUINAULT, Eric DESNOUX Impact of Oxygen Transport Properties on the Kinetic Modeling of Polypropylene Thermal Oxidation. II. Effect of Oxygen Diffusivity - Journal of Applied Polymer Science - Vol. 132, p.1-11 2015 


\title{
Impact of Oxygen Transport Properties on the Kinetic Modeling of Polypropylene Thermal Oxidation. II. Effect of Oxygen Diffusivity
}

\author{
Alexandre François-Heude, ${ }^{1,2}$ Emmanuel Richaud, ${ }^{1}$ Alain Guinault, ${ }^{1}$ Eric Desnoux ${ }^{2}$ Xavier Colin $^{1}$ \\ ${ }^{1}$ Arts et Metiers ParisTech, PIMM Laboratory, CNRS UMR 8006, Paris, France \\ ${ }^{2}$ Renault, DETC-A, Guyancourt, France \\ Correspondence to: A. François-Heude (E-mail: Alexandre.FRANCOIS-HEUDE@ensam.eu)
}

\begin{abstract}
The kinetic model, established in a previous article (François-Heude et al., J. Appl. Polym. Sci., in press) to predict the homogeneous oxidation in iPP films typically thinner than $100 \mu \mathrm{m}$, is now extended to simulate the oxidation profiles in thicker plates by coupling the oxygen diffusion and its consumption by the chemical reactions. In this perspective, oxygen transport properties (namely oxygen solubility, diffusivity, and permeability) are measured by permeametry on a reference iPP. These values are compared with an exhaustive compilation of literature data to evaluate their variability among the whole iPP family, which one has been reasonably ascribed to initial differences in polymer morphology, but also to evaluate their consistency, especially their temperature dependence between 20 and $140^{\circ} \mathrm{C}$. Failing to simulate oxidation profiles, the kinetic model is then used as an inverse resolution method for estimating more satisfactory values of oxygen transport properties. It is thus evidenced that the crystallinity changes induced by thermal oxidation largely explains the dramatic decrease in oxygen penetration toward the sample core just after the induction period. A strategy aimed for introducing the relationship between the polymer crystalline morphology and oxygen transport properties into the kinetic model is given in the graphical abstract, although the effect of polymer polarity remains to be established prior to this implementation.
\end{abstract}

KEYWORDS: ageing; crystallization; degradation; kinetics; morphology

\section{INTRODUCTION}

It is well known that the oxidative degradation of thick polymer plates (typically few mm thick) is restricted to a superficial layer whose thickness impacts their mechanical properties (in particular their fracture properties) when it reaches a critical value ${ }^{1}$ which is, for instance, of the order of one hundred of microns for polyethylene (see Refs. 2 and 3). Basing on this observation, several authors have attempted to determine the thickness of oxidized layer (TOL) in polymers by using a large variety of analytical techniques, for instance: optical microscopy, FTIR spectrophotometry, nanoindentation, etc. The reader may consult Reference 4 for an outstanding review on these techniques. The simplest method consists in determining the overall oxidation rate of polymer samples of different thicknesses to deduce the critical thickness $\left(L_{c}\right)$ above which oxidation gradients appear. Indeed, $L_{c}$ is approximately equal to twice of TOL. At this time, many doubts exist on the real order of magnitude of TOL in isotactic polypropylene (iPP) for which values apparently contradictory ranging from 10 to 100 microns have been reported in the literature as well for thermal $^{5-11}$ as for photothermal aging ${ }^{12}$ in air (see Table I).
It must be recall that oxidation products profiles result from the diffusion control of the oxidation kinetics. These profiles can be satisfactorily predicted as well by analytical ${ }^{2,3,8,10,13,14}$ as by numerical kinetic models ${ }^{6}$ by introducing the Fick's second law into the balance equation governing the oxygen consumption by the chemical reaction with the polymer. Assuming that the oxygen diffusivity $\left(D_{\mathrm{O} 2}\right)$ is independent of the conversion degree of oxidation or time, this equation can be written:

$$
\partial\left[\mathrm{O}_{2}\right] /_{\partial t}=D_{\mathrm{O}_{2}}{ }^{\partial^{2}\left[\mathrm{O}_{2}\right]} /_{\partial z^{2}}-r\left(\left[\mathrm{O}_{2}\right]\right)
$$

with $r\left(\left[\mathrm{O}_{2}\right]\right)$ the term accounting for the oxygen consumption in an elementary sublayer at the depth $z$ in the sample thickness.

Oxygen diffusivity could thus appear as the relevant parameter governing the oxygen supply from the surface towards the specimen core. However, the realistic description of the oxygen consumption is a crucial step in the lifetime prediction approach: indeed, the better the description of oxidation reaction is, the more accurate the simulation of oxidation profiles will be. This connection between the shape of oxidation profiles and the local polymer reactivity in respect to oxygen was particularly 
Table I. Thicknesses of Oxidized Layer Reported in the Literature for iPP Thermal Oxidation

\begin{tabular}{|c|c|c|}
\hline Reference & $\begin{array}{l}\text { Exposure } \\
\text { conditions }\end{array}$ & $\mathrm{TOL}=L_{c} / 2$ \\
\hline Boss and Chien $^{11}$ & $150^{\circ} \mathrm{C}$ & $>75 \mu \mathrm{m}$ \\
\hline Kiryushskin and Shlyapnikov ${ }^{9}$ & $130^{\circ} \mathrm{C}$ & $20 \mu \mathrm{m}$ \\
\hline Gutiérrez et al ${ }^{8}$ & $110^{\circ} \mathrm{C}$ & $10 \mu \mathrm{m}$ \\
\hline Gugumus $^{12}$ & $80^{\circ} \mathrm{C}$ & $60 \mu \mathrm{m}$ \\
\hline Fayolle ${ }^{6}$ & $70^{\circ} \mathrm{C}$ & $20 \mu \mathrm{m}$ \\
\hline
\end{tabular}

highlighted by Boss and Chien ${ }^{10}$ who evidenced a misleading attribution of the changes in the overall oxidation rate to the limiting effect of oxygen diffusion, instead of the effect of oxygen partial pressure. This consideration can be illustrated by the interrelationship between the three oxygen transport properties, namely permeability $P e_{\mathrm{O} 2}$, diffusivity $\mathrm{D}_{\mathrm{O} 2}$ and solubility $S_{\mathrm{O} 2}$, in the semicrystalline polymer:

$$
P e_{\mathrm{O}_{2}}=D_{\mathrm{O}_{2}} \cdot S_{\mathrm{O}_{2}}
$$

This is the reason why it was decided to study separately both phenomena (i.e. oxygen diffusion and chemical consumption), first by focusing on polymer reactivity at the local scale, that is to say on homogeneously degraded iPP films. ${ }^{15}$ This approach requires an accurate measurement of oxygen transport properties, from the transitory and steady-state regimes of permeation using the time-lag method, on a reference iPP. It is advisable to compare these values to an exhaustive compilation of literature data, as started with $S_{\mathrm{O} 2}$ in the first part, ${ }^{15}$ and extended to $D_{\mathrm{O} 2}$ and $\mathrm{Pe}_{\mathrm{O} 2}$ in this second part of this study. The main objective consists in checking the validity of the Arrhenius law for describing their temperature dependence, since these parameters are extrapolated to simulate the PP thermal oxidation at temperatures higher than for their measurement.

The introduction into the kinetic model of variability on $S_{\mathrm{O} 2}$ has allowed to account for the large scattering of induction periods and oxidation rates, as well as their oxygen pressure dependences, reported in the literature for the whole iPP family. ${ }^{15}$ This variability was found to be in line with the scattering of $S_{\mathrm{O} 2}$ values compiled from the literature, which can be reasonably ascribed to differences in iPP morphology, that is to say differences in its ability to crystallize into different lattices (polymorphism), or to the presence of stereo-defects distribution materialized by an average length of isotactic sequences. The issue is now to quantify the variability of $D_{\mathrm{O} 2}$ over the whole iPP family, since it is well-known that this coefficient is also impacted by morphological differences, such as: crystallinity ratio; nature, size, shape, and orientation of crystallites; but also chain orientation in amorphous phase (i.e. segmental mobility of the constrained tie-molecules). ${ }^{16}$ The reader may consult Ref. 17 for an outstanding review. In addition, it was shown by permeametry that oxygen transport properties change along the course of photothermal oxidation. ${ }^{18}$ However, these experiments were performed at ambient temperature after thermal aging to prevent further oxidation during the permeability measurements themselves.
From this rapid literature survey, the key issue are: Can the variability on $D_{\mathrm{O} 2}$ explain the large scattering of iPP oxidation behaviors evidenced in the literature? Can their morphological differences explain the variability of TOL? The kinetic modeling approach is proposed here as an original tool to overcome the experimental difficulties in determining the oxygen transport properties of aged samples. Values of $D_{\mathrm{O} 2}$ and $S_{\mathrm{O} 2}$ will be determined by inverse resolution method to simulate the oxidation profiles of a reference iPP, but also of other iPP samples previously investigated in the literature. Then, it will be interesting to check in which extent the kinetic modeling approach remains valid and how can be integrated the morphological differences into the kinetic model.

\section{EXPERIMENTAL}

\section{Materials}

The iPP under investigation was supplied by Aldrich (under the reference 427,888$)$. Its main physico-chemical characteristics are MFI $\left(230^{\circ} \mathrm{C}, 2.16 \mathrm{~kg}\right)=12 \mathrm{~g} / 10 \mathrm{~min}, M_{w}=250 \mathrm{~kg} \mathrm{~mol}{ }^{-1}$, $M_{n}=67 \mathrm{~kg} \mathrm{~mol}^{-1}$, and PI $=3.7$. IPP plates with a thickness of $2 \mathrm{~mm}$ were made by stacking of about 25 thin iPP films (with a thickness of $80 \mu \mathrm{m})$ in a Gibitre press during $2 \mathrm{~min}$ at $140^{\circ} \mathrm{C}$ under $20 \mathrm{MPa}$. These films were previously obtained by compression molding (during $1 \mathrm{~min}$ at $200^{\circ} \mathrm{C}$ under $20 \mathrm{MPa}$ ) and purified from their stabilizers (Soxhlet extraction for $48 \mathrm{~h}$ using dichloromethane as solvent). Plates were transparent, without bubble, free of most of their additives and without any change in crystalline morphology. Despite a careful purification, the low residual concentration of stabilizers required a correction of the statistical bias in OIT.

\section{Thermal Aging and Physico-Chemical Characterization}

Plates were thermally aged between 60 and $140^{\circ} \mathrm{C}$ in airventilated ovens regulated at $\pm 1^{\circ} \mathrm{C}$. After aging, they were delaminated with a cutter and each elementary film was analyzed separately by FTIR spectrophotometry in transmission mode (Perkin-Elmer spectrophotometer, 16 scans, resolution of $\left.4 \mathrm{~cm}^{-1}\right)$ basing on the carbonyl peak at $1713 \mathrm{~cm}^{-1}(\varepsilon=300 \mathrm{~L}$ $\left.\mathrm{mol}^{-1} \mathrm{~cm}^{-1}\right)$.

Differential scanning calorimetry (DSC) was performed on $10 \mathrm{mg}$ sample weight with a TA Q1000 calorimeter under a

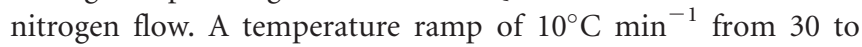
$200^{\circ} \mathrm{C}$ was applied to minimize the annealing phenomena. Crystallinity ratios were calculated taking a melting enthalpy for crystalline lamellae of $\Delta \mathrm{H}_{m}^{0}=209 \mathrm{~J} \mathrm{~g}^{-1}$. The initial crystallinity value was $45 \pm 3 \%$ wt.

No significant changes in crystallinity ratio were observed by DSC along the course of thermal oxidation, but increases up to $25 \%$ were observed by FTIR spectrophotometry on iPP samples of $80 \mu \mathrm{m}$ thickness (see Appendix A) basing on the following correlation, ${ }^{19}$ beforehand checked to give similar results than WAXS:

$$
\chi_{c}(\%)=109 *\left(\frac{A_{997}-A_{917}}{A_{973}-A_{917}}\right)-31.4
$$

where $A_{997}, A_{973}$, and $A_{917}$ are the respective optical densities at 997, 973, and $917 \mathrm{~cm}^{-1}$. 


\section{Oxygen Permeability Tests}

Oxygen permeability was performed with a Systech 8001 device on films of about $130 \mu \mathrm{m}$ thick at 10,23 , and $45^{\circ} \mathrm{C}$ and $0 \%$ of relative humidity. Their active surface area was equal to $50 \mathrm{~cm}^{2}$. The time-lag method was chosen to measure the oxygen transport properties (see for instance Ref. 20). This analysis mode required a complete purge of the system (including detector, pipes, and samples) under a pure nitrogen flow, up to $0.4 \mathrm{ppm}$ as baseline, prior to introduce pure oxygen gas. The diffusivity was calculated by intercepting, with the $\mathrm{x}$-abscissa, the straight-line describing the steady-state regime of the kinetic curve of cumulated oxygen amount $Q_{\mathrm{O} 2}$ obtained by integrating the kinetic curve of Oxygen Transmission Rate along time. For a semi-infinite film of thickness $L$, this straight-line obeys the following general equation:

$$
Q=\alpha\left(t-\frac{L^{2}}{6 D_{\mathrm{O}_{2}}}\right)
$$

where $\alpha$ is a constant.

Therefore, the oxygen diffusivity $D_{\mathrm{O} 2}$ is given by:

$$
D_{\mathrm{O}_{2}}=\frac{L^{2}}{6 t_{\mathrm{Q}=0}}
$$

where $t_{Q}=0$ is the time-lag.

Oxygen solubility $S_{\mathrm{O} 2}$ is related to oxygen diffusivity $D_{\mathrm{O} 2}$ and permeability $\mathrm{Pe}_{\mathrm{O} 2}$ by eq. (2).

\section{KINETIC MODELING}

Since the kinetic model has been detailed in the first part of this study, ${ }^{1}$ its main features will be briefly reminded here. The chemistry of iPP thermal oxidation at solid state is described by a simplified mechanistic scheme which had been successfully applied at molten state in previous articles. ${ }^{21,22}$ It is assumed that methyne units are the main reactive sites. At low to moderate temperature (typically when $T<200^{\circ} \mathrm{C}$ ), oxidation is initiated by the decomposition of its main propagation products: hydroperoxides.

\section{Initiation}

(1u) $\mathrm{POOH} \rightarrow 2 \mathrm{P}^{\circ}+\left(1-\gamma_{1}\right) \mathrm{P}-\mathrm{OH}+\gamma_{1} \mathrm{P}=\mathrm{O}+\mathrm{H}_{2} \mathrm{O}+\gamma_{s} \mathrm{~S}(-2 \mathrm{PH})$ $\left(\mathrm{k}_{1 \mathrm{u}}\right)$

(1b) $2 \mathrm{POOH} \rightarrow \mathrm{P}^{\cdot}+\mathrm{PO}_{2}{ }^{\circ}+\left(1-\gamma_{1}\right) \mathrm{P}-\mathrm{OH}+\gamma_{1} \mathrm{P}=\mathrm{O}+\mathrm{H}_{2} \mathrm{O}+\gamma_{s} \mathrm{~S}$ $\left.-\gamma_{1}\right) \mathrm{P}-\mathrm{OH}+\gamma_{1} \mathrm{P}=\mathrm{O}+\mathrm{H}_{2} \mathrm{O}+\gamma_{\mathrm{s}} \mathrm{S}(-\mathrm{PH})\left(\mathrm{k}_{1 \mathrm{~b}}\right)$

\section{Propagation}

(2) $\mathrm{P}^{\bullet}+\mathrm{O}_{2} \rightarrow \mathrm{PO}_{2}^{\cdot}\left(\mathrm{k}_{2}\right)$

(3) $\mathrm{PO}_{2}^{\cdot}+\mathrm{PH} \rightarrow \mathrm{POOH}+\mathrm{P}^{\bullet}\left(\mathrm{k}_{3}\right)$

\section{Termination}

(4) $\mathrm{P}^{\cdot}+\mathrm{P}^{\cdot} \rightarrow \gamma_{4} \mathrm{P}-\mathrm{P}+\left(1-\gamma_{4}\right) \mathrm{PH}+\left(1-\gamma_{4}\right) \mathrm{F}+\gamma_{4} \mathrm{~B}\left(\mathrm{k}_{4}\right)$

(5) $\mathrm{P}^{\cdot}+\mathrm{PO}_{2} \cdot \rightarrow \gamma_{5} \mathrm{POOP}+\left(1-\gamma_{5}\right) \mathrm{POOH}+\left(1-\gamma_{5}\right) \mathrm{F}+\gamma_{5} \mathrm{~B}\left(\mathrm{k}_{5}\right)$

(6a) $\mathrm{PO}_{2}+\mathrm{PO}_{2} \rightarrow\left[\mathrm{PO}^{\circ} \mathrm{OP}\right]_{\text {cage }}+\mathrm{O}_{2}\left(\mathrm{k}_{6 \mathrm{a}}\right)$

(6b) $\left[\mathrm{PO}{ }^{\circ} \mathrm{OP}\right]_{\text {cage }} \rightarrow \mathrm{POOP}+\mathrm{B}\left(\mathrm{k}_{6 \mathrm{~b}}\right)$

(6d) $\left[\mathrm{PO}^{\circ} \cdot \mathrm{OP}\right]_{\text {cage }} \rightarrow 2 \mathrm{P}^{\bullet}+2\left(1-\gamma_{1}\right) \mathrm{P}-\mathrm{OH}+2 \gamma_{1} \mathrm{P}=\mathrm{O}+2 \gamma_{s} \quad \mathrm{~S}(-$ 2PH) $\left(\mathrm{k}_{6 \mathrm{~d}}\right)$

with the following formalism and initial conditions (concentrations at $t=0$ for any depth $z$ ):
- $\mathrm{PH}$ accounts for the tertiary $\mathrm{CH}$ groups of the polymer chain as unique reactive site, with $[\mathrm{PH}](0, \mathrm{z})=[\mathrm{PH}]_{0}=20.3 \mathrm{~mol}$ $\mathrm{L}^{-1}$

- $\mathrm{P}^{\circ}, \mathrm{PO}_{2}{ }^{\circ}, \mathrm{PO}^{\circ}$ account respectively for alkyl, peroxy, and alkoxy radicals, with $\left[\mathrm{P}^{*}\right](0, \mathrm{z})=\left[\mathrm{PO}_{2}{ }^{\circ}\right] \quad(0, \mathrm{z})=\left[\mathrm{PO}^{\circ} \mathrm{OP}\right]_{\text {cage }}$ $(0, \mathrm{z})=0 \mathrm{~mol} \mathrm{~L}^{-1}$

- $\mathrm{POOH}, \mathrm{POOP}, \mathrm{P}-\mathrm{OH}, \mathrm{P}=\mathrm{O}$ account, respectively, for hydroperoxides, peroxides, alcohols, and ketones as macromolecular oxidation products. The initial concentration of $\mathrm{POOH}$ is kinetically equivalent to the amount of structural defects initially present in the polymer: $[\mathrm{POOH}](0, \mathrm{z})=[\mathrm{POOH}]_{0}=10^{-5}-10^{-1} \mathrm{~mol}$ $\mathrm{L}^{-1}{ }^{23}$

- F, S, and B account, respectively, for double bonds, chain scissions, and $\mathrm{C}-\mathrm{C}$ crosslinks (i.e., covalent bridges).

Each elementary reaction is characterized by its rate constant $k_{i}$. Various yields have been introduced for accounting for the products formation when several competitive elementary processes are involved:

- $\gamma_{s}$ is the yield of $\beta$ scission (leading to ketones), irrespectively of the molecularity of the initiation reaction, in competition with hydrogen abstraction (leading to alcohols):

$$
\gamma_{S}=\frac{k_{\beta \text { scission }}}{k_{\beta \text { scission }}+k_{H \text { abstraction }}}
$$

- From a practical point of view, it is more convenient to determine an apparent yield $\gamma_{1}$ for carbonyl products owing to the high uncertainty on their nature and the value of their molar extinction coefficient at $1713 \mathrm{~cm}^{-1}$.

- $\gamma_{4}$ and $\gamma_{5}$ are the respective yields of alkyl-alkyl and alkylperoxy radicals coupling (of respective rate constants $k_{4 \mathrm{r}}$ and $k_{5 \mathrm{r}}$ ), in competition with disproportionation (of respective rate constants $k_{4 \mathrm{~d}}$ and $k_{5 \mathrm{~d}}$ ):

$$
\gamma_{4}=\frac{k_{4 r}}{k_{4_{r}}+k_{4_{d}}} \text { and } \gamma_{5}=\frac{k_{5 r}}{k_{5_{r}}+k_{5_{d}}}
$$

In this scheme, the bimolecular recombination of peroxy radicals $\mathrm{PO}_{2}{ }^{\circ}+\mathrm{PO}_{2}{ }^{\circ}$ has been detailed. They react together to give cage paired radicals (reaction $6 \mathrm{a}$ ), which can recombine to give a peroxide bridge (reaction 6b), or leave the cage to initiate new oxidation cycles (reaction 6d). Such a series of reactions has been already introduced in previous studies to report for the overall concentration in chain scission, crosslinking and oxidation products determined by Decker et al. ${ }^{24}$ in the case of the radiochemical and thermal ageing of polyethylene, ${ }^{25,26}$ and generalize to iPP. ${ }^{21,22}$ This formalism has the advantage of accounting for the instability of peroxide bridges POOP, through the competition between steps $(6 \mathrm{~b})$ and $(6 \mathrm{~d})$, in polymers where their concentration remains low compared with that of $\mathrm{POOH}$, such as iPP. Indeed, POOP are expected to be as efficient to initiate oxidation as $\mathrm{POOH}$. In contrast, in polyene elastomers (polyisoprene, polybutadiene), their concentration is no longer negligible, because of the addition of peroxy radicals on double bonds. Thus, their thermal decomposition must be added as additional initiation step in the mechanistic scheme. 
Table II. Parameters Used for Kinetic Modeling of iPP Thermal Oxidation

\begin{tabular}{|c|c|c|}
\hline Parameters & $P^{0}$ & Ea $\left(\mathrm{kJ} \mathrm{mol}{ }^{-1}\right)$ \\
\hline$[\mathrm{POOH}]_{\mathrm{O}}\left(\mathrm{mol} \mathrm{L}^{-1}\right)$ & $4 \times 10^{-3}$ & - \\
\hline $\mathrm{So}^{\mathrm{am}}\left(\mathrm{mol} \mathrm{L}^{-1} \mathrm{~Pa}^{-1}\right)$ & $2.5 \times 10^{-6}$ & 6.7 \\
\hline$D_{\mathrm{O} 2}\left(\mathrm{~m}^{2} \mathrm{~s}^{-1}\right)$ & $8.7 \times 10^{-6}$ & 36.4 \\
\hline $\mathrm{Pe}_{\mathrm{O} 2}\left(\mathrm{~cm}^{3} \mathrm{~cm} \mathrm{~cm}^{-2} \mathrm{~Pa}^{-1} \mathrm{~s}^{-1}\right)$ & $2.9 \times 10^{-6}$ & 43.0 \\
\hline$k_{1 u}\left(s^{-1}\right)$ & $2.9 \times 10^{13}$ & 140.7 \\
\hline$k_{1 b}\left(L \mathrm{~mol}^{-1} \mathrm{~s}^{-1}\right)$ & $9.2 \times 10^{8}$ & 95.0 \\
\hline $\mathrm{k}_{2}\left(\mathrm{~L} \mathrm{~mol} \mathrm{~m}^{-1} \mathrm{~s}^{-1}\right)$ & $3.0 \times 10^{9}$ & 10.0 \\
\hline$k_{3}\left(L \mathrm{~mol}^{-1} \mathrm{~s}^{-1}\right)$ & $5.1 \times 10^{7}$ & 62.2 \\
\hline $\mathrm{k}_{4}\left(\mathrm{~L} \mathrm{~mol} \mathrm{~m}^{-1} \mathrm{~s}^{-1}\right)$ & $1.0 \times 10^{12}$ & 0 \\
\hline$k_{5}\left(\mathrm{~L} \mathrm{~mol}^{-1} \mathrm{~s}^{-1}\right)$ & $4.5 \times 10^{10}$ & 0 \\
\hline$k_{6 a}\left(L \mathrm{~mol}^{-1} \mathrm{~s}^{-1}\right)$ & $2.0 \times 10^{17}$ & 90.0 \\
\hline$k_{6 b}\left(s^{-1}\right)$ & $6.7 \times 10^{6}$ & 5.0 \\
\hline$k_{6 d}\left(s^{-1}\right)$ & $1.4 \times 10^{12}$ & 41.0 \\
\hline$\gamma_{1}(\%)$ & 50 & - \\
\hline$\gamma_{4}(\%)$ & 0 & - \\
\hline$\gamma_{5}(\%)$ & 0 & - \\
\hline$\gamma_{s}(\%)$ & 50 & - \\
\hline
\end{tabular}

Obviously, it would be possible to add the formation of an intermediary cage in both other termination steps (4) and (5). However, in this case, the total number of rate constants would exceed our analytical capabilities. That is the reason why such a formalism will be introduced in the mechanistic scheme only when complementary experimental data will be available.

Only the oxygen diffusion has been considered through the second Fick's law as limiting process for the oxidation reaction:

$$
\partial\left[\mathrm{O}_{2}\right] /_{\partial t}=D_{\mathrm{O}_{2}}{ }^{\partial^{2}\left[\mathrm{O}_{2}\right]} /_{\partial z^{2}}-k_{2}\left[\mathrm{P}^{*}\right]\left[\mathrm{O}_{2}\right]+k_{6 a}\left[\mathrm{PO}_{2}^{*}\right]^{2}
$$

where $D_{\mathrm{O} 2}$ is the coefficient of oxygen diffusion into the semicrystalline polymer.

The oxygen concentrations in the amorphous phase, throughout the plate thickness before aging and at the plate surfaces along the course of oxidation, obey the Henry's law:

$$
\begin{gathered}
\forall z, \quad t=0, \quad\left[O_{2}\right](0, z)=C_{s} \\
\forall t>0, \quad z=0, \quad\left[O_{2}\right](t, 0)=\left[O_{2}\right](t, L)=C_{s}
\end{gathered}
$$

where $C_{s}$ is the oxygen concentration in the polymer in equilibrium with the atmosphere under an oxygen partial pressure $P_{\mathrm{O} 2}$ :

$$
C_{s}=P_{\mathrm{O}_{2}} \times S_{\mathrm{O}_{2}}^{a m}
$$

with $S_{\mathrm{O} 2}{ }^{\text {am }}$ the coefficient of oxygen solubility in the polymer, here taken in the amorphous phase, that is, only where oxygen is soluble.

The concentration changes in chemical species are described by a system of ordinary differential equations derived from the previous mechanistic scheme by applying the classical kinetics theory. This system was solved numerically using the ODE15s algorithm of Matlab software recommended for stiff problems of chemical kinetics. ${ }^{27}$ All simulations were performed with a unique set of parameters, determined in the first part of this study [1] and reminded in Table II. These values call for the following comments:

- To simulate as accurately as possible the changes in average molecular weight $\left(M_{n}\right.$ and $\left.M_{W}\right)$, the yields $\gamma_{4}$ and $\gamma_{5}$ have been set to zero. Otherwise, the kinetic model would generate an undesired crosslinking in the early periods of iPP thermal exposure, which would not be realistic at all.

- As expected, the termination rate constants classify in the following order: $k_{4}>k_{5}>k_{6 \mathrm{a}}$, whereas their activation energies classify in the reverse order: $E_{4}<E_{5}<E_{6 a}{ }^{28}$ This is presumably due to the fact that alkyl radicals can easily migrate into the iPP matrix by hydrogen abstraction: $\mathrm{P}^{*}+\mathrm{PH} \rightarrow \mathrm{PH}+\mathrm{P}^{\circ}$, contrarily to peroxy radicals for which: $\mathrm{PO}_{2}{ }^{\circ}+\mathrm{PH} \rightarrow$ $\mathrm{POOH}+\mathrm{P}^{*}$. This transfer reaction does not influence the iPP oxidation kinetics, but it could simply explain the higher mobility and thus, the higher reaction probability of alkyl radicals.

The real concentrations of all chemical species in the semicrystalline polymer have been deduced from the concentrations calculated in the amorphous phase by multiplying them by the volumic fraction of amorphous phase $V_{a}$ :

$$
V_{a}=\chi_{a} \times \frac{\rho_{\text {tot }}}{\rho_{a}}=\left(1-\chi_{c}\right) \times \frac{\rho_{\text {tot }}}{\rho_{a}}
$$

with $\chi_{c}$ the crystallinity ratio, $\rho_{\mathrm{am}}$ the density of the amorphous phase $\left(0.85 \mathrm{~g} \mathrm{~cm}^{-3}\right)$ and $\rho_{\text {tot }}$ the density of the semicrystalline polymer $\left(0.91 \mathrm{~g} \mathrm{~cm}^{-3}\right)$.

\section{RESULTS AND DISCUSSION}

\section{Variability of Oxygen Transport Properties}

Prior to properly calibrate the model, it has been required to determine accurately the input parameters, which are accessible experimentally, that is the oxygen transport properties, namely oxygen permeability $\mathrm{Pe}_{\mathrm{O} 2}$, solubility $\mathrm{S}_{\mathrm{O} 2}$ and diffusivity $D_{\mathrm{O} 2}$. In particular, determining $S_{\mathrm{O} 2}$ was mandatory to determine the different rate constants by inverse resolution method. Permeametry measurements have thus been carried out in the $10-45^{\circ} \mathrm{C}$ temperature range. In this domain, these three parameters reveal an Arrhenian behavior despite a fairly large experimental scattering:

$$
\begin{gathered}
P_{\mathrm{O}_{2}}=2.87 \cdot 10^{-6} \times \exp (-43100 / \mathrm{RT})\left(\mathrm{cm}^{3} \cdot \mathrm{cm} \cdot \mathrm{cm}^{-2} \cdot \mathrm{Pa}^{-1} \cdot \mathrm{s}^{-1}\right) \\
S_{\mathrm{O}_{2}}=1.48 \cdot 10^{-6} \times \exp (-6700 / \mathrm{RT})\left(\mathrm{mol} \cdot \mathrm{L}^{-1} \cdot \mathrm{Pa}^{-1}\right) \\
D_{\mathrm{O}_{2}}=8.65 \cdot 10^{-6} \times \exp (-36400 / \mathrm{RT})\left(\mathrm{m}^{2} \cdot \mathrm{s}^{-1}\right)
\end{gathered}
$$

However, physical transformations can affect the chain mobility and thus lead to discontinuities in Arrhenius graphs, such as the $\alpha$-crystalline phase transitions occurring around $70^{\circ} \mathrm{C}$ as evidenced for instance by DMA. ${ }^{29}$ Owing to these potential deviations from the Arrhenius law, extrapolating at temperatures outside the range of permeation measurement would induce a misestimation of oxygen transport properties. It is thus relevant to position our experimental values among an exhaustive compilation of literature data, as performed for oxygen solubility in 


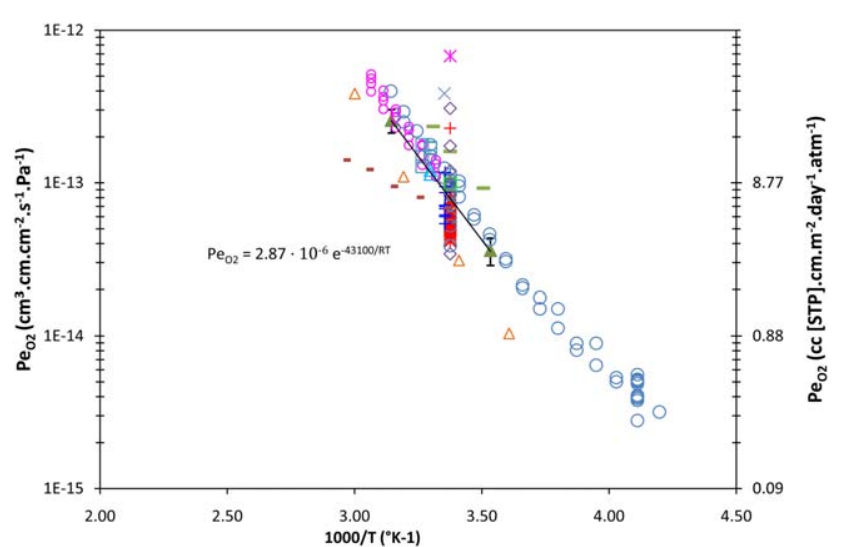

Figure 1. Arrhenius graph of oxygen permeability of iPP between -10 and $60^{\circ} \mathrm{C}$ : $\triangle$ : This work, $*$ : Lin et al., ${ }^{36,37}, \mathrm{O}$ : Somlai et al., ${ }^{39} \mathrm{O}$ : Sezi and Springer, ${ }^{38} \mathbf{-}$ : Villaluenga et al., ${ }^{40}-$ : Beltrame et al., ${ }^{30} \diamond$ : Mani et al., ${ }^{18} \diamond$ : Kiryushskin, ${ }^{8,42} \square$ : Denisov and Afanas'ev, ${ }^{41} \square$ : Modern Plastic Encyclopedia, ${ }^{31}$ +: Taraiya et al., ${ }^{16} \times$ : Kanehashi et al., ${ }^{34} *$ : Frounchi et al., ${ }^{32} \square$ : Incarnato et al., ${ }^{33}+$ : Katsura et al., ${ }^{35} \mathbf{-}$ : Vladimirov et al., ${ }^{76} \square$ : Bikiaris et al., ${ }^{77}$ 口: Kurec et al., ${ }^{43}$ and +: Gutiérrez et al. ${ }^{7}$ [Color figure can be viewed in the online issue, which is available at wileyonlinelibrary.com.]

the first part of this study. ${ }^{15}$ It can be now fulfilled in the case of the oxygen permeability ${ }^{16,18,30-40}$ and diffusivity, ${ }^{18,30,36,37,39-47}$ of which the respective Arrhenius graphs have been depicted in Figures 1 and 2.

In the case of oxygen permeability, our results are fully consistent with the data compiled from the literature ${ }^{16,18,30-40}$ since both datasets are overlapped (Figure 1). This result suggests that our samples were of suitable quality in terms of thickness and morphological features. The rather low scattering (over only one decade) of literature data would only result from differences in crystalline morphologies between the different iPP samples.

In contrast, the values of oxygen diffusivity compiled from the literature $^{18,30,36,37,39-47}$ show a significantly higher scattering ranging over two decades, as previously evidenced for oxygen solubility (Figure 2). The simplest scenario would assume that this additional experimental scattering stems from additional systematic error (instrumental delay effect) in the time-lag measurements, which can occur when this latter is of the same order of magnitude as the characteristic time of the permeameter (i.e. the time needed for gas transport in the lines up to the detector, which depends on the device technology). ${ }^{39}$ In such conditions, the experimental scattering on permeability would be more relevant to apprehend the variability due to initial differences in iPP morphology. However, it can be also envisaged that variation of morphological features would have a reverse effect on oxygen solubility and diffusivity, thereby explaining their higher experimental scattering compared with permeability.

Despite this experimental scattering, the activation energy of oxygen diffusivity seems to remain unchanged in a large range of temperatures, going from glass transition temperature $\left(\sim-10^{\circ} \mathrm{C}\right)$ up to $135^{\circ} \mathrm{C}$, and thus appears consistent with the assumption of Arrhenian behavior for oxygen transport properties.

\section{Simulation of Oxidation Profiles - Impact of Oxidation on Oxygen Transport Properties}

The oxidation profiles have been tentatively simulated by introducing in the kinetic model the oxygen transport properties determined in the previous section [eqs. (14-16)]. As an example, Figure 3 reports simulated and experimental oxidation profiles obtained at 60 and $140^{\circ} \mathrm{C}$ in air.

Clearly, experimental results reveal an oxidation profile more acute than simulated, which implies that the oxygen permeability (and so, the diffusivity) is lower than stated from permeametry measurements. This result confirms the drop in oxygen transport properties during iPP oxidation.

It is thus proposed to determine by inverse resolution method an average value of the oxygen diffusivity, which will enable to simulate more satisfactorily the same oxidation products profile as observed at time $t$. This approach implies that the entire drop in oxygen permeability is ascribed to the diffusion component, thus keeping oxygen solubility constant. Indeed, the model relevancy at the local scale (goodness-of-fit) suggests that the oxygen solubility is properly calibrated and will thereby enable to determine accurately the coefficient of oxygen diffusion.

For various oxidation degrees and temperatures ranged between 60 and $140^{\circ} \mathrm{C}$, oxygen diffusivity was found to be divided by a factor 7 compared with the nominal value $D_{\mathrm{O} 2}$ measured on the reference iPP by permeametry, despite the scattering of experimental data [see eq. (16)]. All the fits at 60, 80, 100, and $140^{\circ} \mathrm{C}$ in air are depicted in Figure 4 . The uncertainty is partly due to the lack of measurements in the first dozens of microns. Our attempts to obtain additional values for smaller depths, by delaminating more oxidized superficial layers or by performing an ATR-FTIR analysis at the extreme sample surface, turns out to be unsuccessful.

Despite the drop in oxygen transport properties, it is possible, by a worst-case approach, to assert that TOL is about $40 \mu \mathrm{m}$ at $140^{\circ} \mathrm{C}$ for the reference iPP and thereby, higher at lower temperatures. Thus, films of $80 \mu \mathrm{m}$ thickness would undergo a

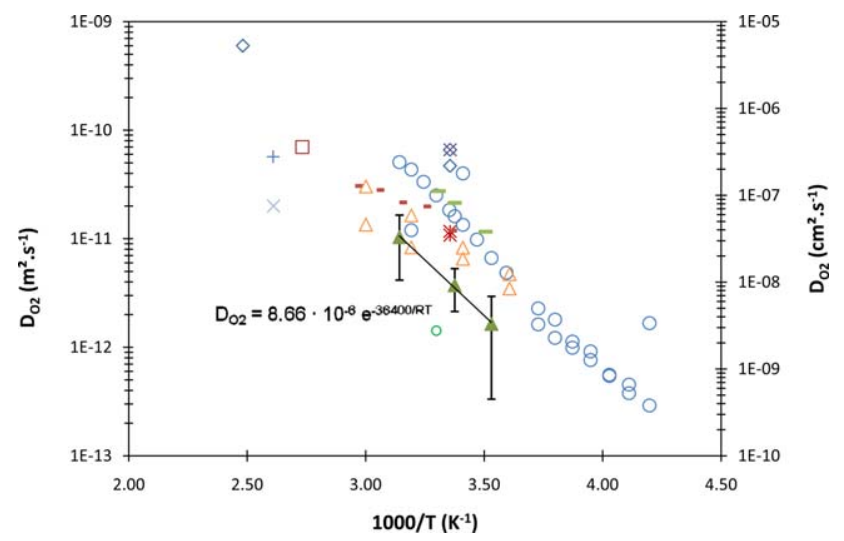

Figure 2. Arrhenius graph of oxygen diffusivity for polypropylene between -10 and $130^{\circ} \mathrm{C}: \Delta$ : This work, $*$ : Lin et al., ${ }^{36,37}$ 口: Somlai et al., ${ }^{39}$ -:Villaluenga et al., ${ }^{40}$ —: Beltrame et al., ${ }^{30} \square$ : Kiryushskin, ${ }^{8,42} \square$ : Denisov and Afanas'ev, ${ }^{41}$ +: Van Krevelen, ${ }^{46}$ 口: Kurek et al., ${ }^{43}$ 口: Stannet, ${ }^{45} \times$ : George's data reported by Jellinek et al., ${ }^{78}$ and $\times$ : Felder et al. ${ }^{79}$ [Color figure can be viewed in the online issue, which is available at wileyonlinelibrary.com.] 

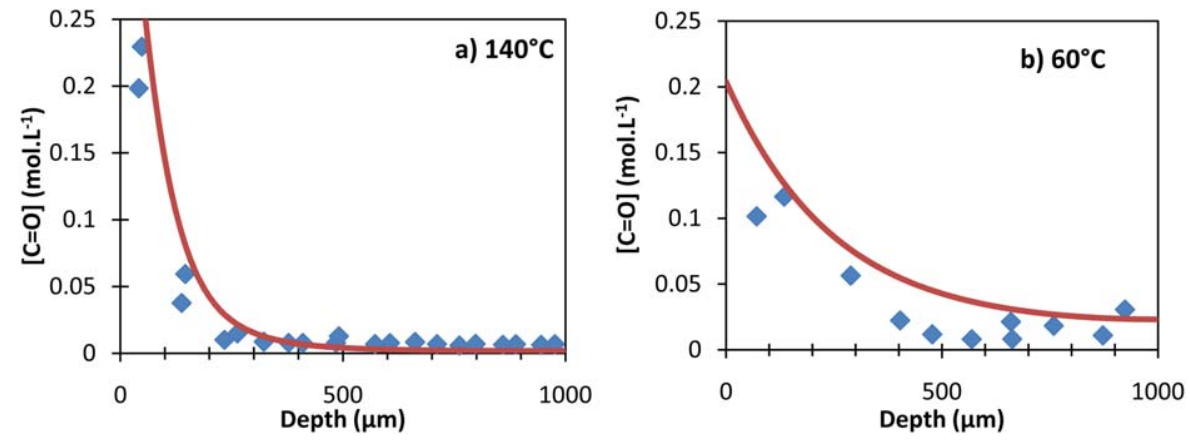

Figure 3. Profiles of carbonyl products in the sample thickness after $3.5 \mathrm{~h}$ at $140^{\circ} \mathrm{C}$ (a) and $1400 \mathrm{~h}$ at $60^{\circ} \mathrm{C}$ in air (b). Symbols: Experimental data. Solid lines: kinetic modeling with $D_{\mathrm{O} 2}$ obeying eq. (16). [Color figure can be viewed in the online issue, which is available at wileyonlinelibrary.com.]

homogeneous oxidation in the temperature range under investigation.

It is relevant to highlight that this observation is not the consequence of any bias introduced by the kinetic modeling approach, since both parameters, which govern the oxidation process, denoted below as "invariant quantities," are properly calibrated on experimental results.

1. The ratio $\mathrm{k}_{2} \cdot \mathrm{S}_{\mathrm{O} 2}{ }^{\mathrm{am}} / \mathrm{k}_{5}$ governs the oxygen pressure dependence of a given polypropylene sample. Thereby, any bias on the determination of the oxygen solubility would be compensated by the adjustment of kinetic rate constants $k_{2}$ or $\mathrm{k}_{5}$. In other words, different combinations of $\mathrm{k}_{2}, \mathrm{k}_{5}$ and $\mathrm{S}_{\mathrm{O} 2}{ }^{a m}$ will enable to simulate the experimental results for the given invariant quantity.
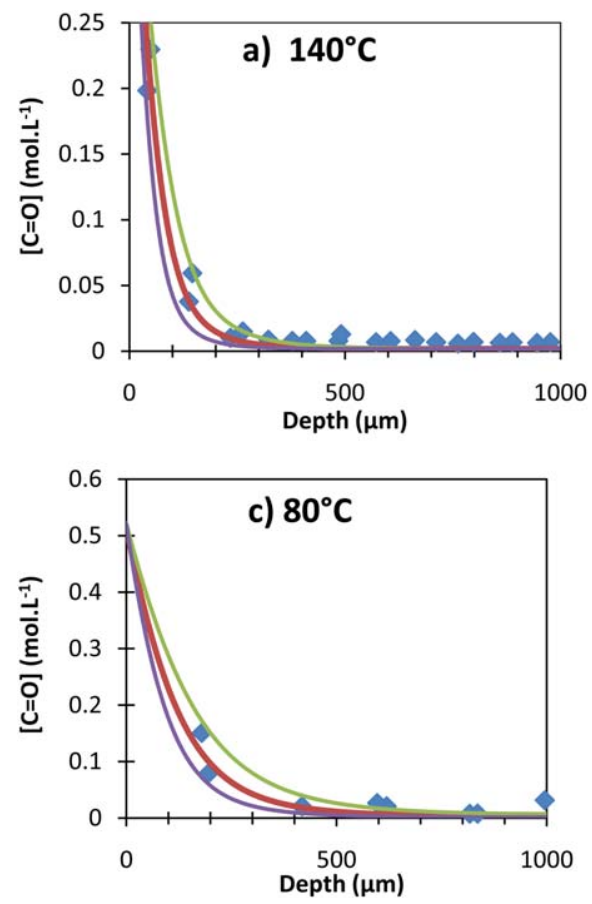

2. The permeability is the relevant quantity, which governs the shape of oxidation profiles. Thus, according to eq. (2), there are also various combinations of $\mathrm{S}_{\mathrm{O} 2}$ and $\mathrm{D}_{\mathrm{O} 2}$, which generate the suitable oxidation profiles. This assertion has been checked by testing different combinations of $\mathrm{k}_{5}, \mathrm{~S}_{\mathrm{O} 2}$ am and $\mathrm{D}_{\mathrm{O} 2}$ leading to a same value of $\mathrm{Pe}_{\mathrm{O} 2}$ and generating an identical oxidation profile.

Values of parameters giving the same values of both invariant quantities are reported in Table III. Since oxygen permeability governs the shape of oxidation profiles, it was selected as the relevant parameter for evaluating the competition between oxygen diffusivity and its consumption by the chemical reaction with the polymer. To account for the wide range of TOL values reported in the literature, the oxidation profiles available in the literature ${ }^{5,9-11,22,47}$ have been collected and have undergone the previous numerical treatment.
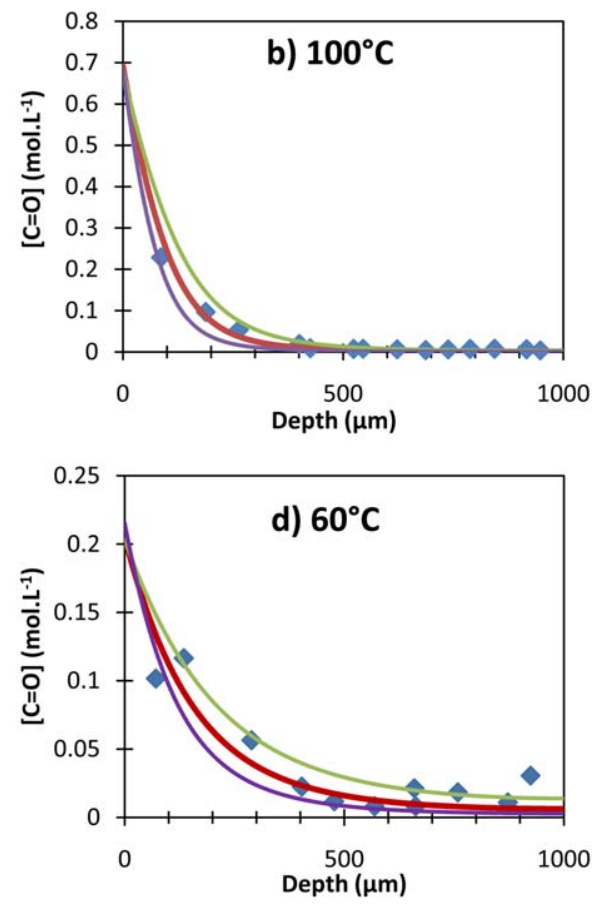

Figure 4. Profiles of carbonyl products in the sample thickness after $3.5 \mathrm{~h}$ at $140^{\circ} \mathrm{C}$ (a), $70 \mathrm{~h}$ at $100^{\circ} \mathrm{C} \mathrm{(b),} 300 \mathrm{~h}$ at $80^{\circ} \mathrm{C}(\mathrm{c})$, and $1400 \mathrm{~h}$ at $60^{\circ} \mathrm{C}$ in air (b) Symbols: Experimental data. Solid lines: kinetic modeling, best fits for $0.14 \times D_{\mathrm{O} 2}$ [given by eq. (18)]. Dotted lines: parametric tests with various multipliers $(0.08$ and 0.25$)$ of the nominal value of $D_{\mathrm{O} 2}$ [given in eq. (16)]. [Color figure can be viewed in the online issue, which is available at wileyonlinelibrary.com.] 
Table III. Values of Parameters Allowing to Simulate Oxidation Profiles (the Most Relevant Values are Given in Bold)

\begin{tabular}{|c|c|c|c|c|}
\hline $\begin{array}{l}\mathrm{Pe}_{\mathrm{O} 2}\left(\mathrm{~cm}^{3} \mathrm{~cm} \mathrm{~cm}^{-2}\right. \\
\left.\mathrm{Pa}^{-1} \mathrm{~s}^{-1}\right)\end{array}$ & $D_{\mathrm{O} 2}\left(\mathrm{~m}^{2} \mathrm{~s}^{-1}\right)$ & $S_{\mathrm{O} 2}\left(\mathrm{~mol} \mathrm{~L}^{-1} \mathrm{~Pa}^{-1}\right)$ & $\mathrm{S}_{\mathrm{O} 2}^{\mathrm{am}}\left(\mathrm{mol} \mathrm{L}^{-1} \mathrm{~Pa}^{-1}\right)$ & $k_{5}\left(\mathrm{~mol} \mathrm{~L}^{-1} \mathrm{~s}^{-1}\right)$ \\
\hline $\begin{array}{l}2.87 \times 10^{-6} \\
\exp (-43,000 / R T)\end{array}$ & $\begin{array}{l}8.65 \times 10^{-6} \\
\exp (-36,400 / R T)\end{array}$ & $\begin{array}{l}1.48 \times 10^{-6} \\
\exp (-6700 / R T)\end{array}$ & $\begin{array}{l}2.51 \times 10^{-6} \\
\exp (-6700 / R T)\end{array}$ & $4.50 \times 10^{10}$ \\
\hline $\begin{array}{l}2.87 \times 10^{-6} \\
\exp (-43,000 / R T)\end{array}$ & $\begin{array}{l}8.65 \times 10^{-7} \\
\exp (-36,400 / R T)\end{array}$ & $\begin{array}{l}1.48 \times 10^{-5} \\
\exp (-6700 / R T)\end{array}$ & $\begin{array}{l}2.51 \times 10^{-5} \\
\exp (-6700 / R T)\end{array}$ & $4.50 \times 10^{11}$ \\
\hline $\begin{array}{l}2.87 \times 10^{-6} \\
\exp (-43,000 / R T)\end{array}$ & $\begin{array}{l}8.65 \times 10^{-8} \\
\exp (-36,400 / R T)\end{array}$ & $\begin{array}{l}1.48 \times 10^{-4} \\
\exp (-6700 / R T)\end{array}$ & $\begin{array}{l}2.51 \times 10^{-4} \\
\exp (-6700 / R T)\end{array}$ & $4.50 \times 10^{12}$ \\
\hline
\end{tabular}

These latter can be advantageously compared with those obtained for the reference iPP. All the permeability values thus determined by using the kinetic model as an inverse resolution method have been reported in the Arrhenius plot depicted in Figure 5.

It is noteworthy that the inverse resolution method allows determining apparent values of oxygen permeability at temperatures higher than the ambient temperature: it seems that only the preexponential factor of $\mathrm{Pe}_{\mathrm{O} 2}$ varies over one decade on both sides of the melting point, whereas the activation energy is weakly impacted.

Generally, the values obtained by the inverse resolution method from oxidation profiles are lower for aged than for nonaged specimens. It is clear that a noticeable part of the $\mathrm{Pe}_{\mathrm{O} 2}$ scattering, materialized by the upper and lower boundaries, stems from the alteration of oxygen transport properties. This result is particularly evidenced on the reference iPP with a decrease in $\mathrm{Pe}_{\mathrm{O} 2}$ by a factor 7, in rather good agreement with the literature data. ${ }^{28}$ Mani et al. ${ }^{18}$ observed that the polypropylene permeability of various gases -namely carbon dioxide, nitrogen, and oxygen- can decrease by a factor ranged between 3 and 10 along the course of oxidation. They attributed this result to a change in crystallinity, the occurrence of chain scissions and crosslinking events, or the formation of photoproducts. Guttierez and coworkers ${ }^{47}$ observed a similar trend for semicrystalline PE (although Mani et al. observed the reverse trend in amorphous LDPE and EPR) that they attributed to chemi-crystallisation, that is to say crystalline rearrangements of the short macromolecular segments created by chain scissions in the amorphous phase. ${ }^{48-50}$

Among all these explanations on the drop in oxygen transport properties, namely chain scissions and crosslinking, crystallinity ratio changes, and photoproducts formation, we will first focus on the two former. According to Rabello and White, ${ }^{48}$ chain scissions and crosslinking would not directly contribute to the decrease in $\mathrm{Pe}_{\mathrm{O} 2}$, but they would promote chemicrystallization, that is to say increase in crystallinity ratio $\chi_{c}$. In our case, no significant change in crystallinity was observed by DSC, whereas FTIR measurements revealed an increase of about $20 \%$, that is to say 9 index points (see appendix).

Basically, this phenomenon is expected to mostly impact oxygen diffusivity whereas photoproducts formation would induce an increase in polymer polarity affecting oxygen solubility. At this stage of investigation, the relationship between $\chi_{c}$ and oxygen solubility $S_{\mathrm{O} 2}$ is not yet available, so this issue is left aside in a first approach.
The ideal strategy for kinetic modeling would consist in expressing the oxygen diffusivity as a function of the amount of chain scissions, as proposed by Guttierez et al. ${ }^{47}$ In a first coarse-grained approach, this would require at first, to calculate the variation of $\chi_{c}$ from the concentration changes in chain scissions $^{51}$ and then, to deduce the impact of this change on $D_{\mathrm{O} 2}$ by using the well-established relationships in the literature. Even for diffusivity of simple gases, a linear correction of the oxygen diffusivity by the volume fraction of the amorphous phase $V_{a}$ is not sufficient to describe such a complex behavior:

$$
D_{\mathrm{O}_{2}}^{\mathrm{cr}}=D_{\mathrm{O}_{2}}^{\mathrm{am}} \cdot V_{a}^{-n}
$$

Indeed, the most widespread models of the literature, developed by Michaels and Bixler ${ }^{52}$ and Peterlin, ${ }^{53,54}$ attempt to describe the influence of crystallites through phenomenological relationships of the form:

$$
D_{\mathrm{O}_{2}}^{\mathrm{cr}}=D_{\mathrm{O}_{2}}^{\mathrm{am}} /_{\tau \beta}
$$

where $\tau$ is the tortuosity factor accounting for the increase in the diffusive pathway owing to the bypass of crystallites, and $\beta$ is the immobilization factor reporting the lowering of the segmental mobility in the amorphous regions near the crystallites

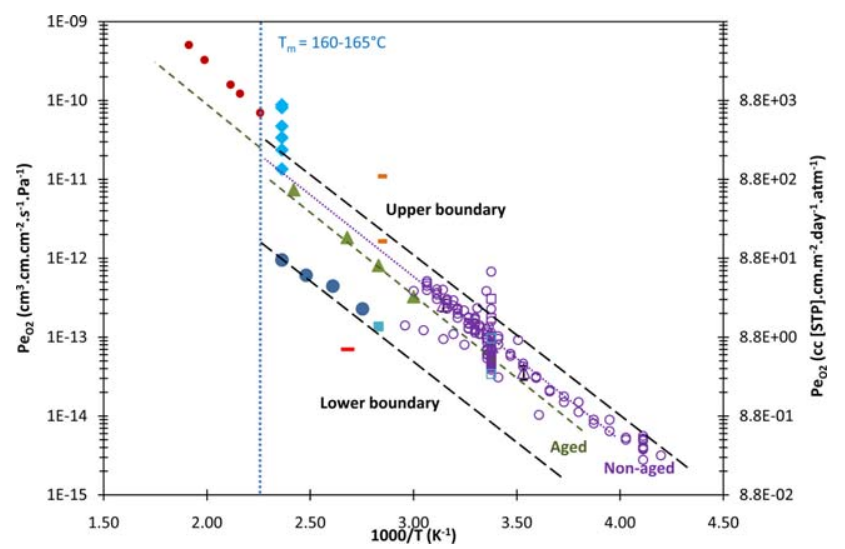

Figure 5. Arrhenius graph of oxygen permeability determined for iPP by permeametry (O: literature, $\triangle$ : reference iPP, $\square$ : By Mani on aged and, $\square$ : unaged specimens ${ }^{18}$ ) or by inverse resolution method from experimental oxidation profiles ( $\mathbf{\Delta}$ : reference iPP, ○: Fayolle, ${ }^{5} \bullet$ : Sarrabi, ${ }^{22}=$ : Gutiérrez et al., ${ }^{7}$ : Boss and Chien, ${ }^{10}=$ : Gugumus, ${ }^{11}$ and $\sqsubset$ : Singh et al. ${ }^{9}$ ). The discontinuity at $160-165^{\circ} \mathrm{C}$ is ascribed to melting point. [Color figure can be viewed in the online issue, which is available at wileyonlinelibrary.com.] 


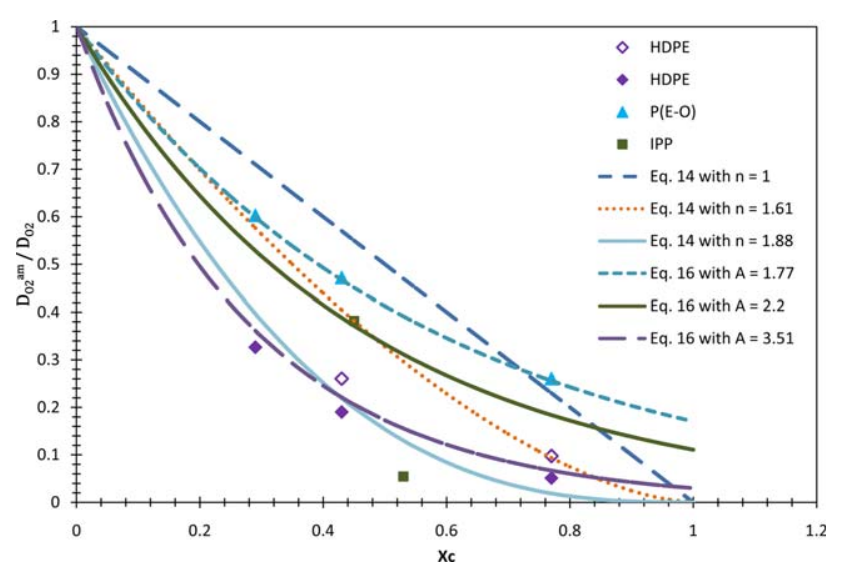

Figure 6. Changes in the ratio $D_{\mathrm{O} 2}{ }^{a m} / D_{\mathrm{O} 2}$ with crystallinity. [Color figure can be viewed in the online issue, which is available at wileyonlinelibrary. com.]

(i.e. of constrained tie-molecules), which depends on the penetrant size.

According to Michaels and Bixler, in semicrystalline polymers, only the tortuosity factor would depend on the volume fraction amorphous phase according to a power law: $V_{a}^{-n, 52}$ with $n=1.61$ for $\mathrm{iPP},{ }^{55}$ compared with $n$ ranging from 1.08 to 1.88 for PE synthesized according to Ziegler-Natta and Philips procedures. $^{52,56}$ This relationship between $n$ and the morphological characteristics cited above has been tentatively established through empirical $^{57}$ or semi-empirical relationships, such as the Fricke's theory adapted by Michaels and Bixler, ${ }^{52}$ or numerical models involving Monte-Carlo algorithms. ${ }^{57-60}$ From these studies, a particular result can be reminded: the relevant impermeable structure are lamellae whose aspect ratio (i.e. shape) and orientation impact the oxygen transport properties, as checked experimentally $^{61}$ and numerically. ${ }^{57,60}$ Therefore, spherulitic structures would have a second order of influence owing to the specific spatial arrangement that they confer to lamellae. ${ }^{60}$

From this standpoint, it is clear that any accurate description of the diffusivity dependence on morphological features would require demanding characterization procedures. Admittedly, it remains possible to use the empirical power law: $V_{a}^{-1.61},{ }^{55}$ but without acquaintance of its validity range. In contrast, the approach of Compañ et al. ${ }^{62}$ consists in giving expressions for the tortuosity and immobilization factors from thermodynamic and free volume theory considerations respectively. Since $\beta$ is closed to unity ( $\beta=1.2$ and $\tau=3.2$ for HDPE Ref. 52 ), it is generally neglected and oxygen diffusivity only depends on crystallinity ratio $\chi_{\mathrm{c}}$ :

$$
D_{\mathrm{O}_{2}} \approx D_{\mathrm{O}_{2}}^{\mathrm{am}} \exp \left(-A(T) \cdot \chi_{c}\right)
$$

with $A(T)$ a weakly temperature dependent constant characteristic of a given material (equal to 3.16 for HDPE Ref. 52 and 1.34 for octane based HDPE Ref. 62 at $25^{\circ} \mathrm{C}$ ).

This kind of relationship has a physical meaning and is easier to use than other models, which require data on lamellae features (aspect ratio and orientation). Our theoretical change in oxygen diffusivity (and so, in permeability) have been calculated with these kinds of relationships (see Figure 6), namely accord- ing to eq. (17) (with $n=1$ and $n=1.61$ ) and eq. (19) (with $A=2.2$ for iPP and $A=1.77$ and 3.51 for HDPE). It is important to precise here that the value of 2.2 has been determined for A by minimizing the gap between eqs. (19) and (17) for the unaged reference iPP (i.e. for $\chi_{c}=0.45$ ).

Whatever the relationship considered, the increase in crystallinity ratio of about $20 \%$ induces a drop in the ratio $D_{\mathrm{O} 2}{ }^{a m} / D_{\mathrm{O} 2}$, which would not exceed $25 \%$, which is very far from the previous observation (division by a factor 7 ). Thus, chemicrystallization alone cannot explain the observed drop in oxygen transport properties. Therefore, the remaining part of this drop could be ascribed to a change in the polymer polarity induced by oxygen grafting onto macromolecules, thus impacting oxygen solubility.

\section{Impact of iPP Thermal Oxidation on the Kinetic Modeling} Anyway, the morphology changes during oxidation are not restricted to crystallinity ratio alone. The specimens underwent crystalline structure modifications as revealed by the shape of melting endotherm, ${ }^{48,63-65}$ which becomes broader and is shifted toward lower temperatures (Figure 7). The reader can refer to review ${ }^{66}$ for further information about iPP polymorphism. These observations can be assigned to the formation of the $\beta$-hexagonal/trigonal or $\delta$-smectic phase $\left(T_{m}=150^{\circ} \mathrm{C}\right)$ at the expense of the initial monoclinic $\alpha$-phase $\left(T_{m}=165^{\circ} \mathrm{C}\right)$, mainly because chain scissions and oxidation products act as structural defects which promote nucleation of the metastable trigonal or smectic phases. On the contrary, annealing would favor the recrystallization of the $\alpha$-phase as a competitive process. $^{64,67,68}$ The difference in the melting temperatures between both phases would be due to the decrease in the lamellae thickness $^{69}$ or the increase in the interfacial energy of lamellae induced by the presence of oxidation products, in better consistency with the scenario of chemicrystallization. ${ }^{48,64,67,68}$ At the microstructural scale, this decrease in melting temperature would be ascribed to the distribution of stereo-defects materialized by the length of crystallisable isotactic sequences rather than to the isotacticity itself. ${ }^{70-75}$

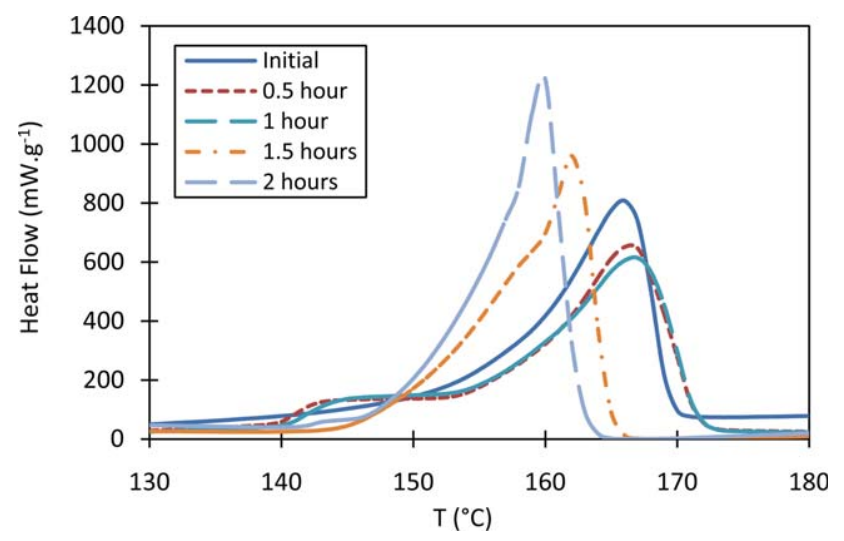

Figure 7. Changes in the shape of melting endotherm at $140^{\circ} \mathrm{C}$ in air (the oxidation induction time is about $1 \mathrm{~h}$ in such aging conditions). [Color figure can be viewed in the online issue, which is available at wileyonlinelibrary.com.] 
These considerations have two important implications. First, the determination of the structure-property relationship between the changes in oxygen diffusivity and crystallinity could be more complicated than expected if only considering the crystallinity ratio. Second, this must be connected with the presumed impact of polymorphism on the apparent value of oxygen solubility. If the variability of solubility is ascribed to the multiplicity of crystal lattices, its value would be affected by the previous morphological changes. This aspect would be a specificity of polypropylene due to the multiplicity of crystalline phases compared with polyethylene. However, the oxygen solubility was kept unchanged considering that the impact on this quantity is of second order. If necessary, it could be described in the kinetic model through the yields in carbonyl products $\gamma_{1}$ and chain scission $\gamma_{s}$. Undoubtedly, this would deserve further considerations.

\section{CONCLUSION}

The main objective of this second part of our study was to tentatively explain the wide range of TOL values reported in the literature, that is, to check the ability of the kinetic model to predict the competition between the oxygen diffusion and its consumption by the chemical reaction with the polymer.

First, the impact of the initial polymer morphology has been evidenced in an exhaustive literature compilation of oxygen transport properties, that is, permeability, diffusivity and solubility. Actually, the experimental scattering is significantly higher on oxygen solubility and diffusivity than on oxygen permeability. This observation is ascribed to:

1. Cumulative errors in the determination of $D_{\mathrm{O} 2}$ and $S_{\mathrm{O} 2}$ by the time-lag method.

2. The changes in both coefficients during thermal exposure due to morphological transformations.

The existence of multiple explanations could hinder the elucidation of structure/transport properties relationships. However, oxygen permeability has been identified as the effective invariant quantity, which governs the shape of oxidation profiles and thus the TOL values.

The literature compilation also enabled to check the relevancy of the Arrhenius behavior observed for $\mathrm{Pe}_{\mathrm{O} 2}, \mathrm{D}_{\mathrm{O} 2}$, and $\mathrm{S}_{\mathrm{O} 2}$ in the $10-45^{\circ} \mathrm{C}$ temperature range (by oxygen permeametry measurements) and postulated at higher temperatures (up to $\left.130^{\circ} \mathrm{C}\right)$.

Anyway, the experimental scattering on oxygen permeability gives a first idea of the impact of the initial polymer morphology on oxygen transport properties. However, it does not enable to report variability on TOL for the whole iPP family. It was thus attempted to determine the apparent value of diffusivity by using the kinetic model as an inverse resolution method on our reference iPP whose oxygen solubility is known. Surprisingly, this latter value was significantly lower than the value measured by permeametry, but seems to still obey an Arrhenius behavior. This observation indicates changes in properties, which would essentially impact the pre-exponential factor, but not the activation energy. This increase in oxygen barrier properties along the course of oxidation is in satisfactory agreement with the permeability values collected in the literature for iPP photooxidation.

These changes would be ascribed to the polymer densification in superficial oxidized layers (oxygen grafting) and the occurrence of morphological changes, such as recrystallization and chemicrystallization phenomena which would respectively result from physical (annealing) and chemical aging (chain scissions). From this standpoint, it is clear that properly simulating oxidation profiles requires establishing the dependence of oxygen transport properties with crystallinity ratio and oxidation conversion degree. In the absence of such a relationship, the validity of the kinetic model would be restrained to moderate degree of oxidation, that is to say for exposure durations just longer than the induction period.

\section{APPENDIX}

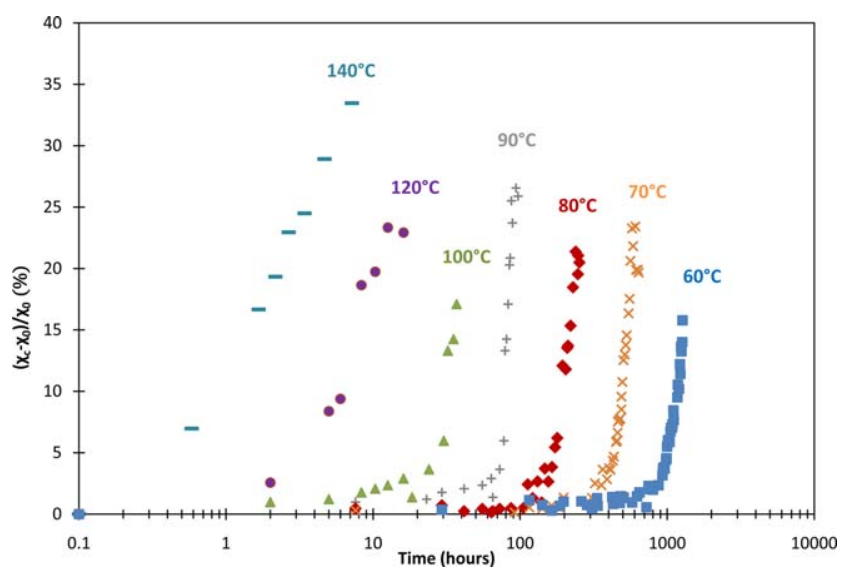

Figure A. Changes in the crystallinity ratio of iPP films of $80 \mu \mathrm{m}$ thick between 60 and $140^{\circ} \mathrm{C}$ in air. Results obtained by FTIR spectrophotometry using eq. (3). [Color figure can be viewed in the online issue, which is available at wileyonlinelibrary.com.]

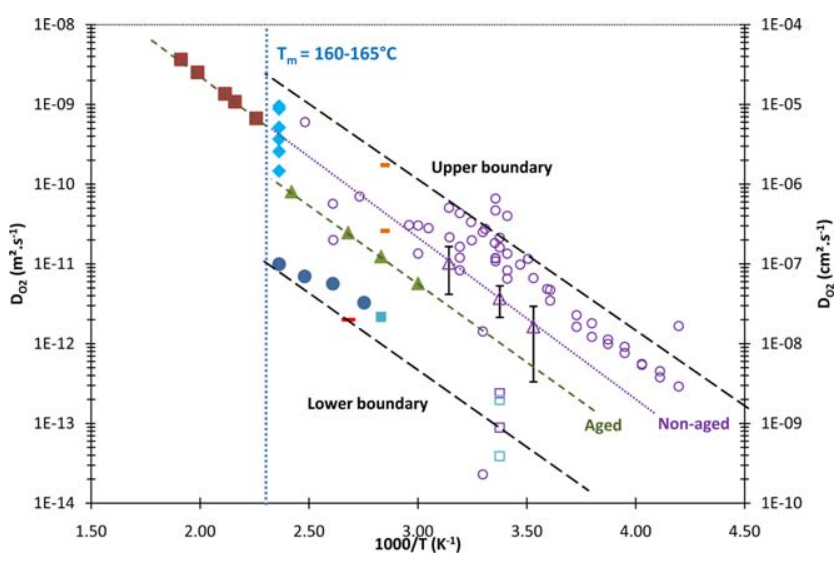

Figure B. Arrhenius graph of oxygen diffusivity determined for iPP by permeametry (O: in the literature, $\triangle$ : reference iPP, $\square$ : By Mani on aged, and $\square$ : nonaged specimens ${ }^{18}$ ) or by inverse resolution method from oxidation profiles ( $\Delta$ : reference iPP, ๑: Fayolle, ${ }^{5} \bullet$ : Sarrabi et al., ${ }^{22}-$ : Gutiérrez et al., ${ }^{7} \square$ : Boss and Chien, ${ }^{10}=$ : Gugumus, ${ }^{11}$ 口: Singh et al. $\left.{ }^{9}\right)$. The discontinuity at $160-165^{\circ} \mathrm{C}$ is ascribed to melting point. 


\section{REFERENCES}

1. Schoolenberg, G. E.; Meijer, H. D. F. Polymer 1991, 32, 438.

2. Cunliffe, A. V.; Davis, A. Polym. Degrad. Stab. 1982, 4, 17.

3. Furneaux, G. C.; Ledbury, K. J.; Davis, A. Polym. Degrad. Stab. 1981, 3, 431.

4. Gillen, K. T.; Clough, R. L. In Techniques for monitoring heterogeneous oxidation of polymers; Dekker, M., Cheremisinoff, N. P., Ed.; Handbook of Polymer Science and Technology: New York, 1989.

5. Fayolle, B. PhD thesis, Paris: Ecole Nationale Supérieure des Arts et Métiers, 2001.

6. Rincon, R. L. M.; Fayolle, B.; Audouin, L.; Verdu, J. Polym. Degrad. Stab. 2001, 74, 177.

7. Gutiérrez, G.; Fayolle, F.; Régnier, G.; Medina, J. Polym. Degrad. Stab. 2010, 95, 1708.

8. Kiryushkin, S. G.; Shlyapnikov, Y. A. Polym. Degrad. Stab. 1989, 23, 185.

9. Singh, R. P.; Mani, R.; Sivaram, S.; Lacoste, J.; Lemaire, J. Polym. Int. 1993, 32, 189.

10. Boss, C. R.; Chien, J. C. W. J. Polym. Sci. Part A-1: Polym. Chem. 1966, 4, 1543.

11. Gugumus, F. Polym. Degrad. Stab. 1998, 62, 245.

12. Girois, S.; Delprat, P.; Audouin, L.; Verdu, J. Polym. Degrad. Stab. 1997, 56, 169.

13. Jansen, K. M. B. Polym. Eng. Sci. 1994, 34, 1619.

14. Audouin, L.; Langlois, V.; Verdu, J.; de Bruijn, J. C. M. J. Mater. Sci. 1994, 29, 569.

15. François-Heude, A.; Richaud, E.; Guinault, A.; Desnoux, E.; Colin, X. J. Appl. Polym. Sci. to appear.

16. Taraiya, A. K.; Orchard, G. A. J.; Ward, I. M. J. Polym. Sci. Part B: Polym. Phys. 1993, 31, 641.

17. Hedenqvist, M.; Gedde, U. W. Prog. Polym. Sci. 1996, 21, 299.

18. Mani, R.; Singh, R. P.; Sivaram, S.; Lacoste, J.; Lemaire, J. J. Macromol. Sci. Pure Appl. Chem. 1996, 33, 783.

19. Perlin, A. J. Polym. Sci.: Polym. Lett. Ed. 1975, 13, 61.

20. Rutherford, S. W.; Do, D. D. Adsorption 1997, 3, 283.

21. Sarrabi, S.; Colin, X.; Tcharkhtchi, A. J. Appl. Polym. Sci. 2008, 110, 2030.

22. Sarrabi, S.; Colin, X.; Tcharkhtchi, A. J. Appl. Polym. Sci. 2010, 118, 9806.

23. Richaud, E.; Colin, X.; Fayolle, B.; Audouin, L.; Verdu, J. Int. J. Chem. Kinet. 2008, 40, 769.

24. Niki, E.; Decker, C.; Mayo, F. R. J. Polym. Sci.: Polym. Chem. Ed. 1973, 11, 2813.

25. Khelidj, N.; Colin, X.; Audouin, L.; Verdu, J.; MonchyLeroy, C.; Prunier, V. Polym. Degrad. Stab. 2006, 91, 1598.

26. Khelidj, N.; Colin, X.; Audouin, L.; Verdu, J.; MonchyLeroy, C.; Prunier, V. Polym. Degrad. Stab. 2006, 91, 1593.

27. Hairer, E.; Wanner, G. Stiff and Differential-Algebraic Problems; Series in Computational Mathematics; Springer: Berlin, 1996.

28. Gillen, K. T.; Wise, J.; Clough, R. L. Polym. Degrad. Stab. 1995, 47, 149.
29. Gomez-Elvira, J. M.; Tiemblo, P.; Elvira, M.; MatisovaRychla, L.; Rychly, J. Polym. Degrad. Stab. 2004, 85, 873.

30. Beltrame, P. L.; Citterio, C.; Testa, G.; Seves, A. J. Appl. Polym. Sci. 1999, 74, 1941.

31. Brandrup, J.; Immergut, E. H.; Grulke, E. A. Polymer Handbook, 4th ed.; John Wiley \& Sons: New York, 1998.

32. Frounchi, M.; Dadbin, S.; Salehpour, Z.; Noferesti, M. J. Membr. Sci. 2006, 282, 142.

33. Incarnato, L.; Scarfato, P.; Motta, O.; Acierno, D. Polym. Compos. 2000, 21, 354.

34. Kanehashi, S.; Kusakabe, A.; Sato, S.; Nagai, K. J. Membr. Sci. 2010, 365, 40.

35. Katsura, T.; Kamal, M. R.; Utracki, L. A. Polym. Compos. 1985, 6, 282.

36. Lin, Y. J.; Dias, P.; Chen, H. Y.; Chum, S.; Hiltner, A.; Baer, E. Polym. Eng. Sci. 2008, 48, 642.

37. Lin, Y. J.; Dias, P.; Chen, H. Y.; Hiltner, A.; Baer, E. Polymer 2008, 49, 2578.

38. Sezi, R.; Springer, J. Colloid Polym. Sci. 1981, 259, 1170.

39. Somlai, L. S.; Liu, R. Y. F.; Landoll, L. M.; Hiltner, A.; Baer, E. J. Polym. Sci. Part B: Polym. Phys. 2005, 43, 1230.

40. Villaluenga, J. P. G.; Khayet, M.; Lopez-Manchado, M. A.; Valentin, J. L.; Seoane, B.; Mengual, J. I. Eur. Polym. J. 2007, 43, 1132.

41. Denisov, E. T.; Afanas'ev, I. B. Oxidation and Antioxidants in Organic Chemistry and Biochemistry; CRC Press, Taylor and Francis: Boca Raton, 2006.

42. Kiryushkin, S. G. Dissertation, Institute Chemical Physics: Moscow, 1975.

43. Kurek, M.; Klepac, D.; Ščetar, M.; Galić, K.; Valić, S. K.; Liu, Y.; Yang, W. Polym. Bull. 2011, 67, 1293.

44. Thorlaksen, P.; Abildskov, J.; Kontogeorgis, G. M.; Fluid Phase Equilib. 2003, 211, 17.

45. Stannet, V. In Diffusion in Polymers; Park, J. C. G. S., Ed.; Academic Press: New York, 1968. p 41.

46. Van Krevelen, D. W.; Hoftyzer, P. J. Properties of polymers; Elsevier: Amsterdam, 1976.

47. Gutiérrez, G. G. PhD. Thesis, Paris: Arts et metiers ParisTech, 2010.

48. Rabello, M. S.; White, J. R. Polymer 1997, 38, 6379.

49. Craig, I. H.; White, J. R.; Kin, P. C. Polymer 2005, 46, 505.

50. Winslow, F. H.; Aloisio, C. J.; Hawkins, W. L.; Matreyek, W. Chem. Ind. 1963, 1465.

51. Fayolle, B.; Richaud, E.; Colin, X.; Verdu, J. J. Mater. Sci. 2008, 43, 6999.

52. Michaels, A. S.; Bixler, H. J. J. Polym. Sci. 1961, 50, 413.

53. Peterlin, A. Transport properties as an extremely sensitive indicator of the status of the amorphous component in the elastically and plastically deformed semicrystalline polymer. Materials Science Monographs. Elsevier: Athens, Greece, 1984; p 585.

54. Peterlin, A. J. Macromol. Sci. Rev. Macromol. Chem. Phys. 1975, 11, B:57. 
55. Vieth, W.; Wuerth, W. F. J. Appl. Polym. Sci. 1969, 13, 685.

56. Michaels, A. S.; Bixler, H. J.; Fein, H. L. J. Appl. Phys. 1964, 35,3165 .

57. Hadgett, P. M.; Goldbeck-Wood, G.; Windle, A. H. Polymer 2000, 41, 6151.

58. Müller-Plathe, F. Chem. Phys. Lett. 1991, 177, 527.

59. Müller-Plathe, F. J. Chem. Phys. 1992, 96, 3200.

60. Mattozzi, A.; Serralunga, P.; Hedenqvist, M. S.; Gedde, U. W. Polymer 2006, 47, 5588.

61. Michaels, A. S.; Bixler, H. J. J. Polym. Sci. 1961, 50, 393.

62. Compañ, V.; Del Castillo, L. F.; Hernández, S. I.; LópezGonzález, M. M.; Riande, E. J. Polym. Sci. Part B: Polym. Phys. 2010, 48, 634.

63. Mani, R.; Singh, R. P.; Sivaram, S.; Lacoste, J. Polym. J. 1994, 26, 1132.

64. Elvira, M.; Tiemblo, P.; Gómez-Elvira, J. M. Polym. Degrad. Stab. 2004, 83, 509.

65. Tiemblo, P.; Gómez-Elvira, J. M.; García Beltrán, S.; Matisova-Rychla, L.; Rychly, J. Macromolecules 2002, 35, 5922.

66. Brückner, S.; Meille, S. V.; Petraccone, V.; Pirozzi, B. Prog. Polym. Sci. 1991, 16, 361.

67. Guisández, J.; Tiemblo, P.; Gómez-Elvira, J. M. Polym. Degrad. Stab. 2005, 87, 543.
68. Rabello, M. S.; White, J. R. Polymer. 1997, 38, 6389.

69. Alariqi, S. A. S.; Kumar, A. P.; Rao, B. S. M.; Singh, R. P. Polym. Degrad. Stab. 2009, 94, 272.

70. Janimak, J. J.; Cheng, S. Z. D.; Zhang, A.; Hsieh, E. T. Polymer 1992, 33, 728.

71. Virkkunen, V.; Laari, P.; Pitkänen, P.; Sundholm, F. Polymer 2004, 45, 4623.

72. Virkkunen, V.; Laari, P.; Pitkänen, P.; Sundholm, F. Polymer 2004, 45, 3091.

73. Paukkeri, R.; Lehtinen, A. Polymer 1993, 34, 4075.

74. Qian, S.; Igarashi, T.; Nitta, K.-H. J. Macromol. Sci. Phys. 2013, 52, 48.

75. Kang, J.; Wang, B.; Peng, H.; Li, J.; Chen, J.; Gai, J.; Cao, Y.; Li, H.; Yang, F.; Xiang, M. J. Appl. Polym. Sci. 2013, 129, 2663.

76. Vladimirov, V.; Betchev, C.; Vassiliou, A.; Papageorgiou, G.; Bikiaris, D. Compos. Sci. Technol. 2006, 66, 2935.

77. Bikiaris, D.; Vassiliou, A.; Chrissafis, K.; Paraskevopoulos, K. M.; Jannakoudakis, A.; Docoslis, A. Polym. Degrad. Stab. 2008, 93, 952.

78. Jellinek, H. H. G. J. Polym. Sci.: Polym. Lett. Ed. 1982, 20, 599.

79. Felder, R. M.; Spence, R. D.; Ferrel, J. K. J. Appl. Polym. Sci. 1975, 19, 3193. 